\title{
URBANIZAÇÃO RENTÁVEL E QUESTÃO DA MORADIA NO BRASIL: DA FINANCEIRIZAÇÃO À REPRODUÇÃO DOS GRANDES CONJUNTOS HABITACIONAIS, NOVOS E VELHOS PADRÕES
}

\author{
Profitable urbanization and housing question in Brazil: from the financialization to the (re) \\ production of large scale housing projects, nearest and oldest patterns
}

Sharon Dias*

*Doutoranda no PPG em Geografia - UFF - sharonddias@gmail.com.

\begin{abstract}
Resumo: A questão da moradia permanece central para a população, Estado, investidores, empresas, pois faz parte das necessidades mais elementares para reprodução da vida, mas é também veículo condutor da ampliação dos ganhos do capital produtivo e financeiro, seja na forma de subsídios monetários por parte do Estado e garantia de aparato legal, dos financiamentos bancários, da realização de operações urbanas consorciadas (OUC), no caso Brasileiro, ou ainda, na produção em larga escala de moradias, a exemplo dos grandes conjuntos habitacionais para a população empobrecida. Nesse sentido, este trabalho discute como a habitação social tem sido apreendida no atual processo de urbanização capitalista em tempos de financeirização e suas consequências sócio-espaciais na escala local.
\end{abstract}

Palavras-chave: Urbanização rentável; Conjuntos habitacionais; Financeirização.

\begin{abstract}
Housing question remain as a central theme to the population, State, investors, companies, because it is a part of the most basic human needs for reproducing their lives, and as a way to amplify capital gains to those who are investors in production and financial system. Whether in the form of monetary subsidies provided by State, legal apparatus, bank financing, as the accomplishment of consortium urban operations (OUC), in the case of Brazil, or in large-scale production of housing, such as big housing projects for low income families. In this way, this paper discusses how social housing has been involved in the process of capitalist urbanization in financialization times and its socio-spatial consequences on the local scale.
\end{abstract}

Key-words: Profitable urbanization; Housing projects; Financialization.

\section{Introdução}

A processo de urbanização possui na sua essência contradições. Pensar a produção do espaço urbano nos remete a analisar conjuntamente o atual estágio do neoliberalismo, a globalização financeira do capital, bem como a degradação do trabalho e a atuação do Estado e seus rebatimentos na vida cotidiana da população. Neste início do século XXI, fazemos parte de uma sociedade cada vez mais desigual e conflituosa, onde se reproduz o capital mediante a produção de objetos, de bens, de ideologias, de valores de troca.

Desenvolve-se cada vez mais o poder da finança. Esta tem garantido sua hegemonia a medida em que atua em consonância com os preceitos do neoliberalismo, a articulação com o Estado e a globalização (dos mercados) gerando conflitos ao produzir espaços homogêneos e normativos para a população empobrecida nas escala local e internacional, conjugando a ordem próxima e a ordem distante, como trata Lefebvre (2001). Uma das expressões desses conflitos e de suas contradições no processo dialético de produção do espaço urbano está nas formas de habitar as cidades e no cotidiano 
da população.

Acreditamos que a habitação social vem sendo também financeirizada. A hipótese aventada é a de que a produção dos grandes conjuntos habitacionais na atualidade é uma necessidade da urbanização rentável e financeira, ora como ideologia urbanística, ora como forma de escoamento da produção, fator econômico para liquidez de ativos financeiros e disseminação de crédito, mesmo para aqueles e aquelas que não possuem rendimentos e possibilidades de ganho.

Na primeira parte do trabalho, fazemos o debate numa perspectiva crítica sobre os sentidos da urbanização na produção capitalista do espaço, relacionando-o ao atual período de neoliberalismo. Em seguida, discutimos as relações gestadas e em gestação entre a habitação social e o processo de financeirização no Brasil e, como esta, tem sido utilizada compulsoriamente para servir a interesses econômicos e políticos, respondendo de forma insuficiente e perversa as necessidades de reprodução da vida da população empobrecida nos espaços metropolitanos, ao mesmo tempo em que media e reitera os interesses do Estado capitalista, capital imobiliário e capital financeiro. Como estudo de caso, observamos algumas soluções habitacionais "standartizadas" na metrópole Fortaleza e suas contradições urbanas, contradizendo as necessidades da população empobrecida e movimentos sociais, que seguem na busca pelo direito à moradia e pelo direito à cidade em sua pluralidade $\mathrm{e}$ concretude.

\section{Urbanização rentável: seriam as cidades neoliberais?}

Compreendemos que o neoliberalismo exprime uma ação, uma ideia e ideologia, um modo de ser no mundo permeado de contradições que visam sustentar o poder de uma classe, a classe dominante, que detém as mariores riquezas mundiais, grande volume de ações em fundos de pensão, a indústria de seguros, a indústria de produção de bens e serviços e os grupos que hegemonizam o Estado, quando vão de encontro a manutenção das condições de reprodução do capital produtivo e financeiro.

No campo das ações, estas podem ser claramente observadas pelas políticas econômicas e monetárias dos países, a exemplo da taxa de juros, da inflação do preço dos ativos financeiros associadas ao preço das moedas nacionais negociadas no mercado, da dependência em relação ao dólar, na política de exportações, especialmente quando observamos os países da América Latina, a exemplo do Brasil. Também na redução do papel do Estado enquanto garantidor de direitos sociais, concomitante a sua manutenção de sua importância enquanto garantidor das liberdades do mercado, na desregulamentação financeira, na maximização dos lucros de acionistas em detrimento do estímulo a produção de bens e empregos e da execução de orçamento para políticas públicas e direitos universais como saúde, educação, pensões, moradia.

O que a teoria e as práticas neoliberais tem a ver com as cidades? As cidades são o mundo criado pela sociedade através do tempo, são uma forma de sociabilidade que expressam modos de vida, interesses e contradições. Hoje, a maior parte da população mundial vive em espaços urbanos. Elas são alvo de disputas, uma vez que, o solo urbano, a localização, a infraestutura localizada, ou possível de ser estabelecida, e a existência de mercados, possibilita a expansão do capital a medida em que a cidade, como um todo, tem valor. Nelas se consome, nelas se produz, nelas se distinguem classes sociais. Não somente a terra na cidade tem valor, mas o conjunto de relações sociais e de possibilidades de reproduzir as ideias e as ações neoliberais, necessitam das cidades. Assim, o processo de urbanização e produção do espaço nas cidades tem sido tensionado pela necessidade de absorver o capital no contexto do neoliberalismo e, mais recentemente, pela hegemonia da financeirização.

Nesse sentido, o processo de urbanização das cidades é uma das formas de realização do capital através de grandes projetos urbanos que, muitas vezes, envolvem capital internacional e modificam, inclusive, a configuração das cidades, a exemplo do que aconteceu e acontece nas grandes cidades como Nova York, Paris, Barcelona, Rio de Janeiro, Fortaleza, São Paulo, dentre outras. Isso se realiza com a construção de rodovias, empreendimentos imobiliários, shoppings, resorts, condomínios, na preparação para recebimentos de megaeventos esportivos, na revitalização de áreas classificadas 
como degradadas (para alguns), na construção de grandes conjuntos habitacionais, etc. Seria o que Brunhoff denomina de "a urbanização rentável" (2010). Poderíamos dizer que seria uma forma de liquidez de ativos, sendo a cidade o título comercializado. Concordamos ainda com Treanor quando este afirma que:

In neoliberal regional policy, cities are selling themselves in a national and global marketplace of cities. They are considered equivalent to an entrepreneur selling a product, but the product is the city (or region) as a location for entrepreneurs. The successful 'sale' of the product is the decision of an entrepreneur to locate there, not simply the sale of land or factories (TREANOR, 2005, s/p) ${ }^{1}$.

No entanto, para que a cidade neoliberal se realize é preciso uma forte atuação do Estado, o que novamente contrapõe a ideia de que na teoria e na prática neoliberal o Estado estaria ausente ou sem poderes. 0 que existe de fato é a permanência do poder do Estado a serviço da garantia da liquidez dos ativos financeiros e imobiliários, concebendo a cidade contraditoriamente, uma vez que a produção do espaço nas cidades, é possível de ser hegemonizada, mas ela não acontece sem que os diversos segmentos da população também o façam. Por isso, a cidade é expressão do capitalismo e do neoliberalismo, mas é também um campo de disputas. Assim, torna-se necessário pensar o Estado em sua amplitude e ações, também como este tem atuado sobre as cidades e sobre a questão da moradia, a qual consiste numa das necessidades mais elementares nesses espaços.

\section{Financeirização e sua influência na produção da habitação social no Brasil}

Financeirização: "atividade financeira como centro estratégico de lucro" (BRUNHOFF, 2010). Para Gutmann:

Não importa o nome pelo qual é chamado: o novo regime é dirigido pelas finanças. 0 seu atributo central é um processo amplamente referido como financeirização, que Epstein definiu como "[...] o aumento do papel dos motivos financeiros, mercados financeiros, atores financeiros e instituições financeiras nas operações das economias nacionais e internacionais" (2008, p. 12)

Numa perspectiva envolta pela economia política, Aalbers (2016) conceitua a financeirização como sendo:

The increasing dominance of financial actors, markets, practices, measurements and narratives, at various scales, resulting in a estructural transformation of economies, firms (including financial institutions), states and households (2016, p. 2) 22.

Pensar a financeirização é pensar também que ela faz parte do modelo de desenvolvimento capitalista nas ultimas décadas. Tivemos um período emblemático de um Estado de bem-estar social nos Estados Unidos e na Europa, versus a ocorrência de várias ditaduras na América Latina, especialmente na década de 1970 e 1980. Isso reflete no desenvolvimento geográfico desigual onde é preciso atentar também para a crise do modelo Fordista de produção à época que acontece com a progressiva queda das taxas de juros, retração do Produto Interno Bruto (PIB) de vários países e do

\footnotetext{
${ }^{1}$ Na política neoliberal regional, cidades estão vendendo a si próprias em um mercado nacional e global de cidades. Eles são considerados equivalentes a um empreendedor que vende um produto, mas o produto é a cidade (ou região) como um local para empreendedores. A "venda" bem sucedida do produto é a decisão de um empresário para localizar nela, não simplesmente a venda de terrenos ou fábricas (tradução nossa).

${ }^{2}$ A crescente dominância dos atores financeiros, mercados, práticas, quantificação e narrativas, em várias escalas, resultando em uma transformação estrutural de economias, firmas (incluindo instituições financeiras), Estados e famílias. (Tradução nossa).
} 
declínio do comércio internacional.

A reação capitalista à crise do modelo Fordista, crise de produção dos padrões de consumo a acumulação, aconteceu ao mesmo tempo em que chegaram ao poder de governos neoliberais em países do ocidente, acarretando uma mudança global na estrutura do mercado mundial devido a inserção de novas tecnologias de informação e a integração dos mercados financeiros a escala global. Chesnay (2010), aborda a existência de um novo estilo de acumulação baseado na centralização do capital financeiro no domínio dos investidores institucionais, especialmente dos fundos de pensão, dos fundos mútuos, dos fundos de aplicação e gestão das carteiras de títulos, da indústria de seguros (de vida, aposentadorias complementares, etc.), e dos fundos de investimento capazes de diminuir os riscos das ações, ou seja, sociedade anônimas.

Esse estilo de acumulação sob a hegemonia das finanças possui algumas características basilares: acelerada inflação do preço dos ativos financeiros, especialmente das ações de multinacionais associado ao preço das moedas nacionais negociadas no mercado, bem como a alta especulação do preço das ações dos serviços das dívidas públicas (Chesnay, 2010). Nesse sentido, pensar a financeirização é pensar também a globalização que passou a ser a recuperação da possibilidade de expansão do capital e a obtenção de lucros graças à liberalização, a desregulamentação dos mercados e das relações de trabalho, e ao grande poder de alcance das tecnologias de informação e comunicação. Força-se a abertura das economias nacionais e a elevada mobilidade de fluxos financeiros. Aqui, o Estado tem papel estratégico a medida em que é através dele que novas regulações e desregulamentações são promovidas. Para Chesnay (et al., 2010, p. 16):

Por meio da estreita interconexão entre as dimensões produtivas e financeiras do processo de mundialização, os mercados financeiros transformam-se numa poderosa força a pressionar o Estado e os setores competitivos não monopolistas a se submeterem àqueles imperativos da valorização da finança.

A dimensão do Estado é capturada pelas finanças e a serviço delas. As economias periféricas se abrem à mobilidade internacional dos capitais, ou seja, a mundialização financeira. Nesse quadro, a moradia, o mercado imobiliário e as políticas habitacionais aparecem intrinsecamente ligadas ao processo de financeirização, uma vez que o incentivo ao crédito para aquisição de imóveis, a conexão entre políticas habitacionais e econômicas, a regulamentação do setor imobiliário, o endividamento, a produção e consumo de ativos imobiliários, a abertura de capitais nas bolsas de valores por empresas da construção civil e do setor imobiliário, demonstram o quão complexo é pensar a questão da moradia e torna visível suas conexões com os mecanismos da financeirização:

The mechanism of the financialization of housing comes in different empirical forms: the securitization of mortgage loans, the rise of subprime and predatory lending, rising mortgage debt for households, the entry of private equity firms, hedeg funds and publicly listed real estate firms in subsidized rental markets, and finally the reliance of non-profit housing associations on social housing bonds and complicated financial derivatives (AALBERS, 2016, P. 3) ${ }^{3}$.

Assim, mediante a globalização e a financeirização os proprietários de moradias se conectam aos investidores globais, ainda que sem pleno conhecimento dessa corelação. Para pensar a financeirização e a questão da moradia, bem como seus diferentes reflexos e manifestações espaciais, é preciso situar o processo de urbanização de cada país e levar em consideração que o capitalismo,

\footnotetext{
30 mecanismo da financeirização da moradia vem em diferentes formas empíricas: a securitização de empréstimos hipotecários, o aumento do predatório crédito subprime, o aumento da dívida hipotecária das famílias, a inserção de firmas privadas, dos fundos hedge e de empresas imobiliárias listadas como sendo de mercado de aluguel e, finalmente, a associação de associações de moradia sem fins lucrativos em habitação social e complicados derivativos financeiros (Tradução nossa).
} 
mesmo como sistema único, se manifesta de formas diferenciadas nos territórios, é possível observar claramente essas variações se observamos seu desenvolvimento em países de economia mais liberalizada e países periféricos, que possuem formas distintas de liberalização.

Compreender a forma como se manifesta o capitalismo no Brasil e suas especificidades nos ajuda à pensar sua questão da moradia vinculada a produção do espaço nacional nas diferentes escalas, a isso, soma-se a forma como se deu sua urbanização, tardia e desigual, sem romper as estruturas agrárias e políticas. Necessário também, pensar a forma como o Estado e sua relação com o mercado de crédito e imobiliário na elaboração e execução da política habitacional brasileira, que hoje evidenciamos estar também envolta no processo de financeirização da economia, do mercado, das relações.

No Brasil a política habitacional torna-se forte e economicamente interessante para o mercado a partir da criação do Sistema Financeiro de Habitação (SFH) e o Banco Nacional de Habitação (BNH) na década de 1960, durante o regime militar. A criação de ambos, estimulou a indústria nacional da construção civil e as instituições de crédito imobiliário. Tanto que 3 anos após a criação do SFH, empresas do setor se reuniram e fundaram a Associação Brasileira das Entidades de Crédito Imobiliário e Poupança (Abecip), que opera nos dias atuais.

A partir desse período, a habitação popular passou a ser promovida em larga escala, sobretudo nas periferias metropolitanas, sendo coordenada pelo governo federal em parceria com as Companhias de Habitação (Cohabs) de caráter estadual, subsequentemente, havendo a participação também do setor bancário nacional. A expressão material e sócio-espacial desse período, que se estendeu até a década de 1980, foi a consolidação dos grandes conjuntos habitacionais (Imagens 1 e 2), enquanto intervenção para a solução dos problemas habitacional da classe trabalhadora, mas também como de interesse rentável do mercado imobiliário para com moradias populares.
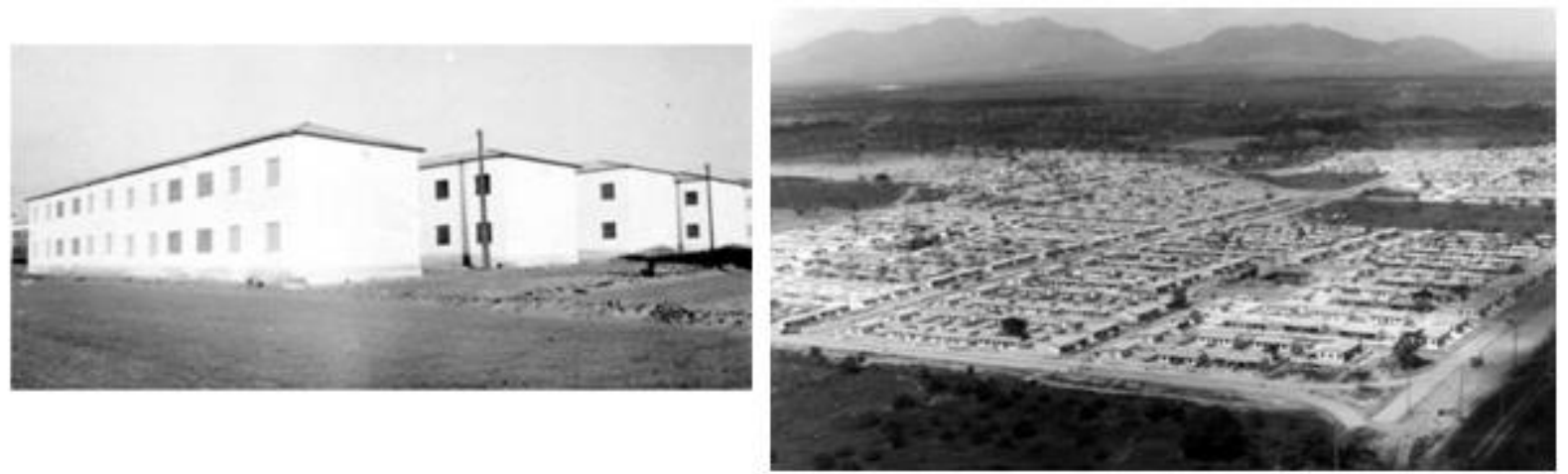

Imagens 1 e 2: Conjunto habitacional Esperança e conjunto habitacional Prefeito José Walter (Década de 1970)

Fonte: Máximo e Pequeno et al (2010)/Arquivo digital (Blog Fortaleza em Fotos, 2012).

Uma lógica que se mostrou rentável com a "creditização" da população mais empobrecida e a produção de habitação popular em larga escala, seguindo a lógica da produção industrial de objetos, onde barateia-se o custo unitário do produto a medida em que se produz em grandes quantidades. Nas décadas que seguiram a criação do BNH, produziram-se moradias populares no Brasil de formas bastantes rentáveis.

Após o encerramento das atividades do BNH, o período de redemocratização no Brasil contou com a reestruturação das esferas de governo e de suas competências, passando-se aos municípios muitas transferindo aos municípios responsabilidades que antes eram da esfera federal. No âmbito da política habitacional nacional, os anos pós pós constituição de 1988 até meados dos anos 2000, período do governo do Presidente Fernando Henrique Cardoso (FHC) não contou com grandes programas estruturantes e ações voltadas para a produção de moradias. No entanto, naquele período foi 
formulado um importante marco regulatório para o crescimento do setor financeiro e mercado de crédito deste setor com a formulação e, posterior aprovação da lei no 9.514 de 20 de novembro de 1997 que dispõe sobre o Sistema de Financiamento Imobiliário (SFI) e a alienação fiduciária de imóveis (BRASIL, 1997).

Em 2004, o sistema foi complementado com a aprovação da lei no 10.931/2004 que, por sua vez, dispõe sobre o patrimônio de afetação de incorporações imobiliárias, a letra de Crédito Imobiliário, a cédula de crédito imobiliário, cédula de crédito bancário e dá outras providências (BRASIL, 2004). A partir de então, desenhou-se um ambiente institucional e de mercado, assim como melhorias no poder de compra da população para o aquecimento do setor imobiliário. Programas estruturantes também foram criados para aquecer o mercado imobiliário, como o Programa de Aceleração do Crescimento (PAC) e, posteriormente, no cenário da recente crise americana de 2007, em que foi criado o programa Minha Casa, Minha Vida (MCMV).

O Programa de Aceleração do Crescimento (PAC) foi lançado durante o Governo do ex-Presidente Luís Inácio Lula da Silva (2002 - 2010/PT) no início do ano de 2007 para investir em diversas ações infraestruturais nas cidades brasileiras, tais como construção de rodovias, saneamento, portos e também habitação. Os investimentos do programa em Fortaleza na área habitacional giraram em torno de 100 milhões de reais. No entanto, muitas das obras não chegaram a ser concluídas em função dos problemas na esfera do governo local.

Já o programa Minha Casa, Minha Vida, por sua vez, foi criado em 2009 com a prerrogativa de solucionar inegável déficit habitacional brasileiro também no mandato de do ex-Presidente Lula. Para tanto, o pacote de soluções do programa englobava subsídios financeiros para a aquisição da casa própria por famílias de classe média e, mediante o banco Caixa Econômica, realizava a contratação de projetos pautados por construtoras de grande, médio e pequeno porte para a produção de habitação popular, destinada a faixa de 0 a 3 salários.

No tocante à produção da habitação popular observa-se que desde o momento de sua formulação, que remetia à crise americana de 2008, até às regras para construção, classificação das faixas de renda dos beneficiários, dos padrões habitacionais concebidos e possíveis para cada pessoa, que variam em função da renda, ou seja, das possibilidades de pagamento da moradia, e a forma de contratação das empresas para executá-lo, que trata-se de um programa econômico (AMORE, 2015). À esse respeito, ao analisar a financeirização da política habitacional brasileira, Royer afirma que:

De meta objetiva das políticas do setor, o "combate ao déficit", expressão largamente utilizada na mídia impressa e televisiva, tem sido utilizado como pretexto para a criação de novos instrumentos de crédito, mais vocacionados à acumulação financeira de capital que à universalização do direito à moradia (ROYER, 2013, P. 25).

Mesmo após décadas do início de uma política habitacional de grande porte, as políticas atuais perpetuam o modelo de reprodução dos grandes conjuntos habitacionais quando se trata de habitação popular (Imagens 3 e 4). 


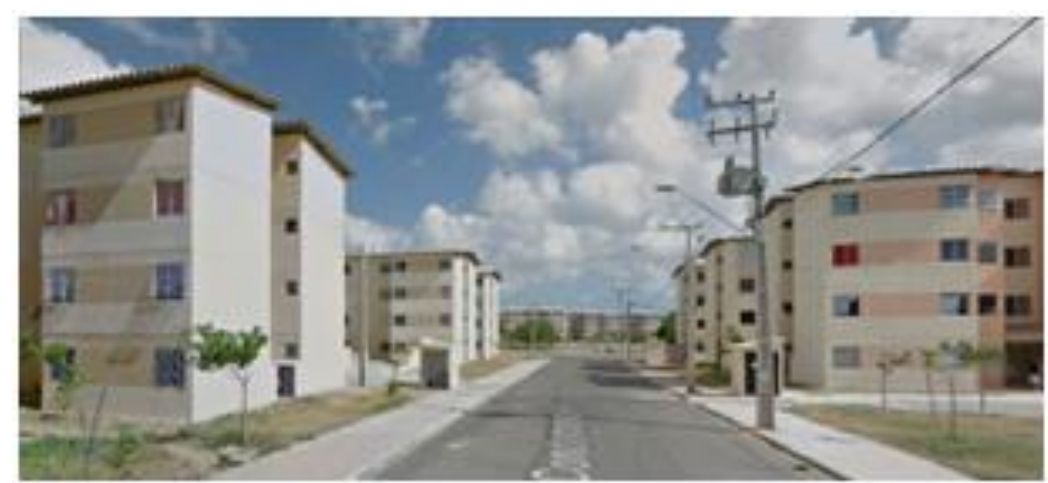

Imagem 3: Residencial Cidade Jardim em Fortaleza, Brasil

Fonte: Google Maps (2016)

Dessa forma, é possível perceber a articulação entre os setores produtivos e financeiros junto ao Estado, no que diz respeito a regulamentação de marcos legais e o incentivo a produção de moradias em massa, uma forma persistente de execução da política habitacional brasileira. Ainda que existam outras possibilidades de provimento de moradia considerando as necessidades da população e as questões locais, regionais, ambientais.

\section{Considerações Finais}

Buscamos, compreender as intersecções entre setores produtivos e financeiros na promoção da habitação social e seus impactos na escala urbana e regional. Mesmo após décadas do início de uma política habitacional de grande porte, as políticas atuais perpetuam o modelo de reprodução dos grandes conjuntos habitacionais quando se trata de habitação popular. Dessa forma, é possível perceber a articulação entre os setores produtivos e financeiros junto ao Estado, no que diz respeito a regulamentação de marcos legais e o incentivo a produção de moradias em massa, uma forma persistente de execução da política habitacional brasileira. Ainda que existam outras possibilidades de provimento de moradia considerando as necessidades da população e as questões locais, regionais, ambientais, esta, permanece como uma constante no quadro de desenvolvimento da habitação social no território nacional.

\section{Referências}

AALBERS, Manuel. The Financialization of Housing: a political economy approach. $1^{\mathrm{a}}$ Ed. New York, NY. Routledge, 2016.

BAN, Cornel. Brazil's liberal neo-developmentalism: New paradigm or edited orthodoxy? In: Review of International Political Economy 2012, iFirst: 1-34

CARLOS, Ana Fani Alessandri. O lugar no/do mundo. São Paulo: FFLCH, 2007.

CARVALHO Alba Maria Pinho de et al. Políticas públicas e o dilema de enfrentamento das desigualdades: um olhar crítico sobre a América Latina no século XXI. In. Carleial, Adelita Neto (Org.). Poder e políticas públicas na América Latina. Fortaleza: UFC, 2010.

CHESNAIS, François; SERFATI, Claude; DOMINIQUE Pihon. SALAMA, Pierre; FARNETTI, Richard. GUTTMANN, Robert; BRUNHOFF, Suzanne de. A mundialização financeira: gênese, custos e riscos. São Paulo: Xamã, 1998.

CHESNAIS, François (org.). A finança mundializada: raízes sociais e políticas, configuração, consequências. São Paulo: Boitempo, 2005. 
BOSCHI, Renato. Politics and Trajectory in Brazilian Capitalism developments. In U.

BRUNHOFF, Suzanne de et al. A finança capitalista. São Paulo: Alameda, 2010.

DE PAULA, Luiz Fernando; FRITZ, Barbara; PRATES, Daniela M. Center and Periphery in International Monetary Relations: Implications for Macroeconomic Policies in Emerging Economies, desiguALdades.net Working Paper Series 80, Berlin: desiguALdades.net International Research Network on Interdependent Inequalities in Latin America. 2015

GEORGE, Susan. A Short History of Neo-liberalism: Twenty years of Elite Economics and Emerging Opportunities for Structural Change. Entrevista. Disponível em: http://base.socioeco.org/docs/doc94_en.pdf, Acessado em 12 de janeiro de 2017.

GUTTMANN, Robert. Uma introdução ao capitalismo dirigido pelas finanças. Revista Novos Estudos, CEBRAP 82,novembro 2008 pp. 11-33

HARVEY, David. A produção capitalista do espaço. São Paulo: Annablume 2005

. Neoliberalismo: história e implicações. 4aㅡ Ed. - São Paulo. Edições Loiola, 2013.

17 Contradições e o fim do capitalismo. 1a Ed. São Paulo. Boitempo, 2016.

LEFEBVRE, Henri. A revolução urbana. Belo Horizonte: Ed UFMG, 1999.

O direito à Cidade. São Paulo: Editora Centauro, 2001.

Espaço e política. Belo Horizonte: UFMG, 2008.

MÁXIMO, Rérisson; LOPES, João Marcos de A.; PEQUENO, Renato. Políticas Habitacionais e Produção do Ambiente Construído Em Fortaleza: algumas facetas dessa relação. In: XIII Encontro Nacional de Tecnologia do Ambiente Construído. Canela - Rio Grande do Sul. 2010.

SCHNEIDER, Ben Ross; SOSKICE, David. Inequality in Developed Countries and Latin America: Coordinated, liberal and Hierarchical systems. In Economy and Society- 17 - 52. 2009.

DIAS, Sharon Darling de Araújo. Do espaço concebido à produção do cotidiano: a experiência do conjunto habitacional Maria Tomásia no bairro Jangurussu em Fortaleza-CE. Dissertação (Mestrado em Geografia Humana). Universidade Estadual do Ceará, Fortaleza: 2013.

THEBORN G. Pós-neoliberalismo II: que Estado para que democracia? In: BORON, Atilio A. et al. (Orgs.). As teorias do Estado e seus desafios no fim do século. Petrópoles, RJ: Vozes, 1999.

TREANOR, Paul. Neoliberalism: origins, theory, definition. In: http://web.inter.nl.net/users/Paul.Treanor/neoliberalism.html, s/a. Acessado em: 08.01.2017 